\title{
From ultrahigh to extreme field magnetic resonance: where physics, biology and medicine meet
}

\author{
Thoralf Niendorf $^{1} \cdot$ Markus Barth $^{2} \cdot$ Frank Kober $^{3} \cdot$ Siegfried Trattnig $^{4}$
}

Published online: 24 May 2016

(c) ESMRMB 2016

The development of ultrahigh-field magnetic resonance (UHF-MR) is moving forward at an amazing speed that is breaking through technical barriers almost as fast as they appear. UHF-MR has become an engine for innovation in experimental and clinical research [1-11]. With more than 35,000 MR examinations already performed at 7.0 Tesla, the reasons for moving UHF-MR into clinical applications are more compelling than ever. The value of high-field MR has already proven itself many times over at lower field strengths; now 7.0 T has opened a window on tissues, organs and (patho)physiological processes that have been largely inaccessible in the past. Images from these instruments have revealed new aspects of the anatomy, functions and physio-metabolic characteristics of the brain, heart, joints, kidneys, liver, eye and other organs/tissues, at an unparalleled quality. The number 35,000 sounds large, but in fact we have barely cracked open the door and have yet to truly assess what lies on the other side.

That makes this a perfect moment for a highly topical special issue of MAGMA: those of us who work in

Thoralf Niendorf

thoralf.niendorf@mdc-berlin.de

1 Berlin Ultrahigh Field Facility (B.U.F.F.), Max-Delbrueck Center for Molecular Medicine in the Helmholtz Association, Robert Roessle Strasse 10, 13125 Berlin, Germany

2 Centre for Advanced Imaging, The University of Queensland, Building 57, Research Road, St Lucia, QLD 4072, Australia

3 Centre de Résonance Magnétique Biologique et Médicale (CRMBM), Aix-Marseille Université, CNRS UMR7339, 13385 Marseille Cedex 05, France

4 High Field MR Center, Department of Biomedical Imaging and Image Guided Therapy, Medical University of Vienna, Währinger Gürtel 18-20, 1090 Vienna, Austria
UHF-MR can see a clear route forward for resolving technological issues and can outline some of the new opportunities that will accompany even higher field strengths. The issue provides an overview of the state of the art and discusses the clinical relevance of what we have already observed and can clearly foresee. Articles are devoted to development of novel methodology [12-16], safety topics [17-19] early multicenter trials [20], frontier human studies [21-28], breakthrough clinical applications [29-36] and future directions of UHF-MR [37, 38]. At the moment some of these new concepts and clinical applications are merely of proof-of-principle nature and visions, but they are compelling enough to drive the field forward. We hope to engage the interest of clinicians, basic scientists, engineers, translational researchers and applied scientists from many areas, and particularly to attract young scientists and new entrants into the field. In doing so, we hope to convince the MR imaging and spectroscopy communities to throw their weight into the task of solving technical problems and conceiving new clinical applications. UHF MR has a staggering number of potential uses in neuroscience, neurology, radiology, cardiology, internal medicine, oncology, nephrology, ophthalmology and other related clinical fields. As they are developed, we will push the boundaries of MR physics, biomedical engineering and biomedical sciences in many other ways.

Another reason this special issue is timely is because physicists, engineers and pioneers from related disciplines have already taken an even further step into the future, in their minds, with something they are calling Extreme Field MR (EF-MR). This envisions human MR at $20 \mathrm{~T}$ [37, 38], and it is an important leap of the imagination because it aims to fill a crucial "resolution gap" in our understanding of human biology [39, 40]. While discoveries are pouring in on the molecular and cellular level every day, it is 
extremely difficult to integrate these findings into a coherent picture of the functions of tissues and pathological processes at a mesoscopic level above that of the cell. There is a wide gap between the view of biologists and clinicians that is begging to be filled. Extreme field MR is probably an ideal technology that will reach between these levels in vivo by bridging a crucial gap in resolution in space and time.

Achieving this goal will certainly require extra resources-and the will to go there. While the first $20 \mathrm{~T}$ class MR instruments will likely be devoted to discovery and to proof of principle, the findings will be crucial guides to making the best use of lower-resolution imaging techniques. The only thing that could keep the dream of human MR at $20 \mathrm{~T}$ from becoming reality would be a failure to follow the path and see what develops. Will the clinic eventually be able to follow us to even higher fields? It always does, if a whole community of experts devotes their creative efforts to the task. Currently we have only the roughest sense of what we will find. But even that glimpse has made some of us believers. We hope that this issue will convey the seeds of this vision and inspire you-as it has us-to become pioneers in these amazingly promising new areas of biomedical research: ultrahigh field and extreme field MR.

\section{Compliance with ethical standards}

Conflict of interest The authors declare that they do not have a conflict of interest with the exception that Thoralf Niendorf is CEO and founder of MRI.TOOLS GmbH, Berlin, Germany.

Ethical standards This editorial does not contain any studies with human participants or animal performed by any of the authors with the exception of references to previously published work included in this editorial.

\section{References}

1. Ugurbil K (2012) The road to functional imaging and ultrahigh fields. Neuroimage 62(2):726-735

2. Moser E, Stahlberg F, Ladd ME, Trattnig S (2012) 7-T MR-from research to clinical applications? NMR Biomed 25(5):695-716

3. Niendorf T, Graessl A, Thalhammer C, Dieringer MA, Kraus O, Santoro D, Fuchs K, Hezel F, Waiczies S, Ittermann B, Winter L (2013) Progress and promises of human cardiac magnetic resonance at ultrahigh fields: a physics perspective. J Magn Reson 229:208-222

4. Ugurbil K (2014) Magnetic resonance imaging at ultrahigh fields. IEEE Trans Biomed Eng 61(5):1364-1379

5. Kraff O, Fischer A, Nagel AM, Monninghoff C, Ladd ME (2015) MRI at 7 Tesla and above: demonstrated and potential capabilities. J Magn Reson Imaging 41(1):13-33

6. Sinnecker T, Kuchling J, Dusek P, Dorr J, Niendorf T, Paul F, Wuerfel J (2015) Ultrahigh field MRI in clinical neuroimmunology: a potential contribution to improved diagnostics and personalised disease management. EPMA J 6(1):16
7. Trattnig S, Bogner W, Gruber S, Szomolanyi P, Juras V, Robinson S, Zbyn S, Haneder S. (2015) Clinical applications at ultrahigh field $(7 \mathrm{~T})$. Where does it make the difference? NMR Biomed. doi:10.1002/nbm.3272 (epub ahead of print)

8. Niendorf T, Paul K, Oezerdem C, Graessl A, Klix S, Huelnhagen T, Hezel F, Rieger J, Waiczies H, Frahm J, Nagel A, Oberacker E, Winter L. (2015) W(h)ither human cardiac and body magnetic resonance at ultrahigh fields? Technical advances, practical considerations, applications, and clinical opportunities. NMR Biomed. doi:10.1002/nbm.3268 (epub ahead of print)

9. van der Kolk AG, Hendrikse J, Zwanenburg JJ, Visser F, Luijten PR (2013) Clinical applications of 7 T MRI in the brain. Eur J Radiol 82(5):708-718

10. Webb AG, Van de Moortele PF. (2015) The technological future of 7 T MRI hardware. NMR Biomed. doi:10.1002/nbm.3315. (Epub ahead of print)

11. Benjamin P, Viessmann O, MacKinnon AD, Jezzard P, Markus HS (2015) 7 Tesla MRI in cerebral small vessel disease. Int J Stroke 10(5):659-664

12. Huettner AM, Nencka AS (2016) Radiofrequency pulse design with numerical optimization in the Fourier domain. Magn Reson Mater Phy 29:313-317

13. Yarach U, Luengviriya $C$, Stucht D, Godenschweger F, Schulze P, Speck O (2016) Correction of B 0-induced geometric distortion variations in prospective motion correction for $7 \mathrm{~T}$ MRI. Magn Reson Mater Phy 29:319-332

14. Desmond HY, Wiggins CJ, Ivanov D, Brenner D, Hoffmann J, Mirkes C, Poser BA (2016) Volumetric imaging with homogenised excitation and static field at 9.4 T. Magn Reson Mater Phy 29:333-345

15. Eggenschwiler F, O'Brien KR, Gallichan D, Gruetter R, Marques JP (2016) 3D T 2-weighted imaging at 7T using dynamic kTpoints on single-transmit MRI systems. Magn Reson Mater Phy 29:347-358

16. Larson PE, Han M, Krug R, Jakary A, Nelson SJ, Vigneron DB, Kelley DA (2015) Ultrashort echo time and zero echo time MRI at 7T. Magn Reson Mater Phy 29:359-370

17. Weidemann G, Seifert F, Hoffmann W, Pfeiffer H, Seemann R, Ittermann B (2016) Measurements of RF power reflected and radiated by multichannel transmit MR coils at 7T. Magn Reson Mater Phy 29:371-378

18. Fatahi M, Demenescu LR, Speck O (2016) Subjective perception of safety in healthy individuals working with 7 T MRI scanners: a retrospective multicenter survey. Magn Reson Mater Phy 29:379-387

19. Chen B, Schoemberg T, Kraff O, Dammann P, Bitz AK, Schlamann M, Wrede KH (2016) Cranial fixation plates in cerebral magnetic resonance imaging: a 3 and 7 Tesla in vivo image quality study. Magn Reson Mater Phy 29:389-398

20. Voelker MN, Kraff O, Brenner D, Wollrab A, Weinberger O, Berger MC, Stöcker T (2016) The traveling heads: multicenter brain imaging at 7 Tesla. Magn Reson Mater Phy 29:399-415

21. de Boer A, Hoogduin JM, Blankestijn PJ, Li X, Luijten PR, Metzger GJ, Leiner T (2016) $7 \mathrm{~T}$ renal MRI: challenges and promises. Magn Reson Mater Phy 29:417-433

22. Cardoso PL, Fischmeister FPS, Dymerska B, Geißler A, Wurnig M, Trattnig S, Robinson SD (2016) Improving the clinical potential of ultra-high field fMRI using a model-free analysis method based on response consistency. Magn Reson Mater Phy 29:435-449

23. Bianciardi M, Toschi N, Eichner C, Polimeni JR, Setsompop K, Brown EN, Hämäläinen MS, Rosen BR, Wald LL (2016) In vivo functional connectome of human brainstem nuclei of the ascending arousal, autonomic, and motor systems by high spatial resolution 7-Tesla fMRI. Magn Reson Mater Phy 29:451-462 
24. Zimmer F, O'Brien K, Bollmann S, Pfeuffer J, Heberlein K, Barth M (2016) Pulsed arterial spin labelling at ultra-high field with a B 1+ -optimised adiabatic labelling pulse. Magn Reson Mater Phy 29:463-473

25. Marrakchi-Kacem L, Vignaud A, Sein J, Germain J, Henry TR, Poupon C, Hertz-Pannier L, Lehéricy S, Colliot P, Moortele P-F, Chupin M (2016) Robust imaging of hippocampal inner structure at 7T: in vivo acquisition protocol and methodological choices. Magn Reson Mater Phy 29:475-489

26. Donadieu M, Le Fur Y, Confort-Gouny S, Le Troter A, Guye M, Ranjeva JP (2016) Evidencing different neurochemical profiles between thalamic nuclei using high resolution 2D-PRESS semiLASER 1H-MRSI at 7 T. Magn Reson Mater Phy 29:491-501

27. Kraff O, Lazik-Palm A, Heule R, Theysohn JM, Bieri O, Quick HH (2016) 7 Tesla quantitative hip MRI: a comparison between TESS and CPMG for T2 mapping. Magn Reson Mater Phy 29:503-512

28. Schreiner MM, Zbýň Š, Schmitt B, Weber M, Domayer S, Windhager R, Mlynárik V (2016) Reproducibility and regional variations of an improved gagCEST protocol for the in vivo evaluation of knee cartilage at 7 T. Magn Reson Mater Phy 29:513-521

29. Li Y, Jakary A, Gillung E, Eisendrath S, Nelson SJ, Mukherjee P, Luks T (2016) Evaluating metabolites in patients with major depressive disorder who received mindfulness-based cognitive therapy and healthy controls using short echo MRSI at 7 Tesla. Magn Reson Mater Phy 29:523-533

30. Schumacher S, Pache F, Bellmann-Strobl J, Behrens J, Dusek P, Harms L, Kister I (2016) Neuromyelitis optica does not impact periventricular venous density versus healthy controls: a 7.0 Tesla MRI clinical study. Magn Reson Mater Phy 29:535-541

31. Cronin MJ, Wharton S, Al-Radaideh A, Constantinescu C, Evangelou N, Bowtell R, Gowland PA (2016) A comparison of phase imaging and quantitative susceptibility mapping in the imaging of multiple sclerosis lesions at ultrahigh field. Magn Reson Mater Phy 29:543-557

32. Zhu C, Haraldsson H, Tian B, Meisel K, Ko N, Lawton M, Saloner D (2016) High resolution imaging of the intracranial vessel wall at 3 and $7 \mathrm{~T}$ using 3D fast spin echo MRI. Magn Reson Mater Phy 29:559-570
33. Beenakker JWM, Ferreira TA, Soemarwoto KP, Genders SW, Teeuwisse WM, Webb AG, Luyten GP (2016) Clinical evaluation of ultra-high-field MRI for three-dimensional visualisation of tumour size in uveal melanoma patients, with direct relevance to treatment planning. Magn Reson Mater Phy 29:571-577

34. Mirkes C, Shajan G, Chadzynski G, Buckenmaier K, Bender B, Scheffler K (2016) 31P CSI of the human brain in healthy subjects and tumor patients at $9.4 \mathrm{~T}$ with a three-layered multinuclear coil: initial results. Magn Reson Mater Phy 29:579-589

35. Compter I, Peerlings J, Eekers DB, Postma AA, Ivanov D, Wiggins CJ, Schijns OE (2016) Technical feasibility of integrating $7 \mathrm{~T}$ anatomical MRI in image-guided radiotherapy of glioblastoma: a preparatory study. Magn Reson Mater Phy 29:591-603

36. Grouiller F, Jorge J, Pittau F, van der Zwaag W, Iannotti GR, Michel CM, Lazeyras F (2016) Presurgical brain mapping in epilepsy using simultaneous EEG and functional MRI at ultrahigh field: feasibility and first results. Magn Reson Mater Phy 29:605-616

37. Budinger T, Bird M, Frydman L, Long J, Mareci T,Rooney W, Rosen B, Schenck J, Schepkin V, Sherry D, Sodickson D, Springer C, Thulborn K, Uğurbil K, Wald L (2016) Toward 20 tesla magnetic resonance for human brain studies: opportunities fordiscovery and neuroscience rationale. Magn Reson Mater Phy 29:617-639

38. Winter L, Niendorf $T$ (2016) Electrodynamics and radiofrequency antenna concepts for human magnetic resonance at 23.5 T (1 GHz) and beyond. Magn Reson Mater Phy 29:641-656

39. Polenova T, Budinger TF (2016) Ultrahigh field NMR and MRI: Science at a crossroads. Report on a jointly-funded NSF, NIH and DOE workshop, held on November 12-13, 2015 in Bethesda, Maryland, USA. J Magn Reson. doi:10.1016/j.jmr.2016.01.008. (Epub ahead of print)

40. Winter L, Oezerdem C, Hoffmann W, van de Lindt T, Periquito J, Ji Y, Ghadjar P, Budach V, Wust P, Niendorf T (2015) Thermal magnetic resonance: physics considerations and electromagnetic field simulations up to 23.5 Tesla $(1 \mathrm{GHz})$. Radiat Oncol 10:201 